\title{
CONSUMISMO: UMA REFLEXÃO ACERCA DAS AQUISIÇÕES NO CAMPO DA MODA
}

\section{CONSUMPTION: A REFLECTION ABOUT ACQUISITIONS IN FASHION FIELD}

ELENIR CARMEN MORGENSTERN, DRA. | UNIVILLE

SILVANA SILVA REITER WITKOSKI | UNIVILLE

\begin{abstract}
RESUMO
O artigo, configurando-se em recorte de pesquisa do Mestrado Profissional em Design, reflete acerca do consumismo na moda, prática excessiva na sociedade contemporânea. A metodologia para o desenvolvimento da investigação pautou-se em pesquisas bibliográficas, analisando os cenários sociais, culturais e mercadológicos, sendo a principal premissa propiciar ao leitor uma perspectiva do ser humano em relação à aquisição de roupas. $\mathrm{O}$ artigo, em seu desdobramento, ancora-se na abordagem histórico-social da moda, a fim de mapear e analisar conjunturas no sistema simbólico da moda (âmbito da ética, da economia e do meio ambiente), relacionando o problema com os agentes consumidores e suas práticas. $O$ alto consumo na moda está interligado a aspectos positivos para a sociedade, como motor da economia e do desenvolvimento, mas traz perdas no âmbito da ética e da moral, sem contar os problemas ambientais. As principais conclusões, baseadas nas reflexões do artigo, referem-se às dificuldades que os movimentos em prol da sustentabilidade encontram, diante da busca por satisfação da sociedade, por meio da aquisição de objetos do desejo.
\end{abstract}

PALAVRAS CHAVE: Consumismo; Moda; Sociedade; Cultura; Sustentabilidade

\begin{abstract}
The article, which is a piece of the research in Professional Master's program in Design, reflects about fashion consumption, considered an excessive practice in the contemporary society. The methodology for the investigation development was based in bibliographic research, analyzing social, cultural and market sceneries, and the main premise is to provide the reader with a perspective of the human being in relation to clothes acquisition. The article is based in the socio-historical fashion approach in order to identify and analyze circumstances in the symbolic system of fashion (ethic, economic and environmental areas), relating the problem to the consumption agents and their practices. The high consumption of fashion is connected to positive aspects for society, as an engine for the economy and development. However, it brings losses to ethic and moral areas, as well as environmental problems. The main conclusions brought up by the reflections in the article are related to the difficulties found by the movements which fight for sustainability. Such difficulties are due to the society search of satisfaction through the acquisition of desire goods.
\end{abstract}

KEY WORDS: Consumption; Fashion; Society; Culture; Sustainability 


\section{INTRODUÇÃO}

Um dos temas abordados nas instituições de ensino superior com foco na sustentabilidade, nas corporações e na sociedade em geral - com preceitos conscientes no tocante ao meio ambiente e ao desenvolvimento sustentável - é o consumo de moda. A sociedade, desde o período da Revolução Industrial, vem aumentando de maneira acelerada o consumo de objetos, com destaque à aquisição de roupas. Essa ânsia pela obtenção de artigos e peças do vestuário, itens muitas vezes supérfluos, transforma o consumo em consumismo, característica da sociedade atual.

Para Leonard (2011), não há problema em consumir para atender às necessidades básicas, mas quando passamos para o consumismo sem controle, com base em desejos, estamos falando em utilizar recursos para uma produção além do necessário e do que o planeta consegue repor. Fora isso, os problemas ambientais, políticos e econômicos são agravados pela degradação resultante do consumismo, que vem aumentado notadamente no século XXI.

Este artigo contextualiza o campo da moda na atual sociedade, associando as práticas dos seus agentes ao consumismo. Mediante a abordagem histórica, no âmbito da ética, da economia e do meio ambiente, relaciona as práticas com os agentes sociais consumidores e analisa causas e efeitos socioculturais. Ainda, apresenta tendências para essa problemática ao citar pesquisas envolvendo grandes empresas, que apontam um cenário diferente da realidade atual, com previsão de uma quarta Revolução Industrial nos setores têxtil e da moda, conhecida como indústria 4.0.

\section{SOCIEDADE E CONSUMO: UMA ABORDAGEM HISTÓRICO-SOCIAL}

O ser humano, em sua história, buscou atender às necessidades básicas, como segurança, alimentação, moradia e vestimenta - aspectos fundamentais para sobreviver com dignidade. Com base em registros desde a Pré-História, sabe-se que as pessoas obtinham carne e couro para a confecção de roupas por intermédio da caça, produziam o seu próprio alimento nas lavouras e, mais tarde, praticavam o escambo, ampliando o acesso aos demais produtos que circulavam em cada época.

Com o desenvolvimento da moeda, os agentes sociais obtiveram poder de compra, adquirindo na sociedade o que precisassem para sua sobrevivência, o que representou um avanço na história da humanidade. Em cada período da história, a relação do ser humano com as aquisições foi estabelecida de maneira evolutiva. Ou seja, quando pôde melhorar a sua situação, por meio da criatividade e abundância de materiais, isso foi feito. Bauman (2008) explica que, por toda a história da humanidade, suprimentos constantes de matéria-prima foram oferecidos, oportunizando ao ser humano moldar a variedade de formas de vida e de padrões de relações, com auxílio da inventividade cultural conduzida pela imaginação.

Nos séculos XVIII e XIX se deu um marco para a sociedade no que se refere à manufatura: a Revolução Industrial. Conforme Pietrocolla (1986, p.14), "a formação da sociedade de consumo teve seus marcos iniciais com a Revolução Industrial, inicialmente verificada na Inglaterra nos fins do século XVIII". A indústria têxtil estava crescendo, e a industrialização trouxe eficiência para os setores produtivos. Forty (2007) apresenta o exemplo da estampagem em tecidos no ano de 1750, momento em que a produção de seis peças diárias passou, em 1796, para 500 peças por dia com a utilização da máquina a vapor. Assim, a produção anual, de um milhão, passou a 16 milhões de peças. Com esse progresso, também veio o ônus para os menos favorecidos, com mudanças necessárias e desnecessárias. Forty (2007, p 19) esclarece que "a máquina a vapor, por exemplo, trouxe maior eficiência à indústria manufatureira e maior velocidade aos transportes, mas sua fabricação ajudou a transformar mestres artesãos em trabalhadores assalariados".

A demanda de produção continuou em ascensão no período entre guerras, que ocorreu no século $X X$, aproximadamente 1918 a 1939, tempo em que muitas das fabricações foram idealizadas para suprir necessidades oriundas daquele período. Penna (1999, p. 28) conta que nos "últimos anos da década de 1980, enquanto a população mundial apresentava um crescimento extraordinário de $120 \%$, a produção global de bens conhecia um aumento ainda mais vertiginoso, de cerca de $400 \% "$.

Na produção têxtil e de roupas em grande escala, a industrialização aumentou a produção com a invenção da máquina de costura, facilitando o trabalho das costureiras, passando do manual para o industrial, porém isso não refletiu num ganho para as profissionais. Segundo Forty (2007, p. 78), "do dinheiro que o sweater ou dono de confecção economiza, parte ia para pagar o custo da máquina, parte para os lucros, mas a maior parte servia para reduzir o preço da costura ao cliente". A figura 1 apresenta uma máquina de costura a vapor, invenção que facilitou o trabalho das costureiras e gerou aumento de produção. 


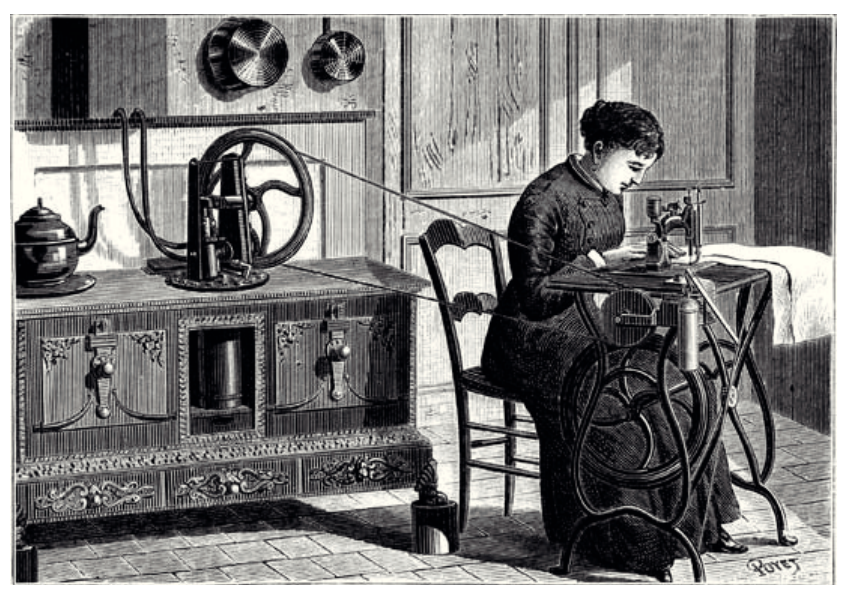

Figura 01: Máquina de costura alimentada por motor a vapor Fonte: disponível em: $<$ http://escola.britannica.com.br/levels/fundamental/article/Revolu\%C3\%A7\%C3\%A30-industrial/481567>

Como ocorreu esse aumento na produção com proporção tão surpreendente? O que mais influenciou para que as indústrias gerassem esse resultado? Pietrocolla (1986) esclarece que esse aumento se deu pela facilidade que o Estado proporcionava para as indústrias se instalarem e trabalharem, com concessões de impostos e tarifas. Sendo a política de desenvolvimento dos países evoluídos baseada na industrialização, sua finalidade primordial eram a produção e o consumo, com retorno por intermédio de impostos. Pietrocolla (1986, p. 13) complementa escrevendo que "a sociedade de consumo tem como meta fundamental produzir mercadorias, vendê-las, produzir outras, vendê-las e assim num eterno círculo vicioso envolve os homens numa rede de relações sociais".

Outro fator determinante que marcou a história da produção e do consumo, principalmente em moda, foi a globalização, focando o livre comércio entre os países, por meio de acordos gerados pelos governos. Com a abertura das fronteiras, as negociações foram facilitadas, sendo mais viável, em alguns casos, importar e/ou terceirizar a confecção de artigos para ter maior margem de lucro.

Evidencia-se, mediante a retrospectiva histórico-social, que o ser humano teve um comportamento incentivado ao consumismo, fosse como dono de um negócio rentável, fosse como usuário final ou como agente da gestão do país. Com a Revolução Industrial, geraram-se demandas de produção, com facilidades proporcionadas pelo governo e, posteriormente, pela globalização. Essa conduta afetou negativamente a sociedade contemporânea, que hoje busca resgatar valores e o zelo com o meio ambiente.

\section{CENÁRIO CONTEMPORÂNEO DA SOCIEDADE CONSUMISTA}

Com base no histórico relatado anteriormente, verifica-se que desde o período da Revolução Industrial a sociedade vem aumentando o consumo em geral, transformando o consumo em consumismo. Barbosa (2004, p. 5) afirma que "sociedade de consumo é um dos inúmeros rótulos utilizados por intelectuais, acadêmicos, jornalistas e profissionais de marketing para se referir à sociedade contemporânea".

O consumo é caracterizado pela compra que atende às necessidades básicas, ou seja, essenciais para o bem-estar da sociedade, como alimento, vestimenta, moradia, transporte, segurança, lazer, entre outros. $O$ consumismo, que caracteriza a sociedade atual, parte do pressuposto de satisfazer a desejos moldados por questões culturais, ambientais ou de marketing, atendendo a um significado simbólico, refletindo em contextos éticos, econômicos e ambientais.

\subsection{Contexto ético do consumismo de moda}

Refletindo acerca de questões éticas da sociedade consumista, encontram-se situações constrangedoras ligadas às corporações, ao governo e até aos clientes finais, todos visando à vantagem própria. As empresas, por meio de incentivos do governo e dos efeitos da globalização, progrediram desde a Revolução Industrial, informatizaram seus processos, automatizaram máquinas, gerando cada vez mais produtividade e, por conseguinte, mais consumo. Nessa obsessão por gerar lucros, as empresas, mais especificamente as do setor têxtil e da moda, partem de alguns pressupostos: eliminar desperdícios em todos os sentidos, deixando os processos mais enxutos; aumentar a produtividade; e reduzir custos, diminuindo o salário dos funcionários, ou pagando o menor valor possível pela fabricação de uma peça para terceirizados. Ou seja, em algum ponto teremos a exploração do trabalho humano mediante baixos salários e, muitas vezes, em condições desumanas.

Segundo Saldanha e Assis (2016, p. 3), "a busca pelo lucro incessante do capitalismo moderno gera uma série de consequências negativas nas esferas sociais e econômicas, a exemplo de doenças físicas e psíquicas". Dessa forma, com a evolução tecnológica e a obtenção de mais lucro por meio da produção, o capitalista, além de aumentar sua riqueza, ainda pode ampliar e diversificar seus negócios.

Essa é a realidade presente no mundo atual. Muitas empresas renomadas do segmento fast fashion negociam com pequenas empresas de países subdesenvolvidos, 
como Bangladesh. Empresários buscam a todo custo prosperar em seus empreendimentos. Para tanto, muitas vezes, são pressionados a aceitar baixos valores por peça do vestuário, com a ameaça da busca pela concorrência. A falta de ética e a inexistência de legislação trabalhista, impondo regras no setor têxtil e de confecção que regulamentem as ações e as negociações realizadas pelas empresas, afetam sempre o mais fraco: os funcionários.

As pessoas consideram como uma oportunidade poder adquirir mercadorias a preços muito abaixo dos praticados na sua localidade, sendo esta uma das únicas preocupações: conseguir uma roupa que satisfaça a seu desejo a um bom preço. Raramente conhecem o caminho que a peça do vestuário percorreu até chegar a suas mãos e ignora que essa atitude pode ser revertida se o consumidor perceber e/ou for informado dessa realidade. Conforme Berlim (2012), emigrantes trabalham em locais com condições de segurança e higiene comprometidas; trabalhadores, crianças e jovens mulheres têm jornada de trabalho de mais de 12 horas por dia; as leis trabalhistas não são cumpridas; e o ser humano é menosprezado pelos donos de confecções, que desrespeitam e tiram proveito da extrema pobreza das comunidades. A figura 2 apresenta trabalho escravo ou análogo ao escravo.

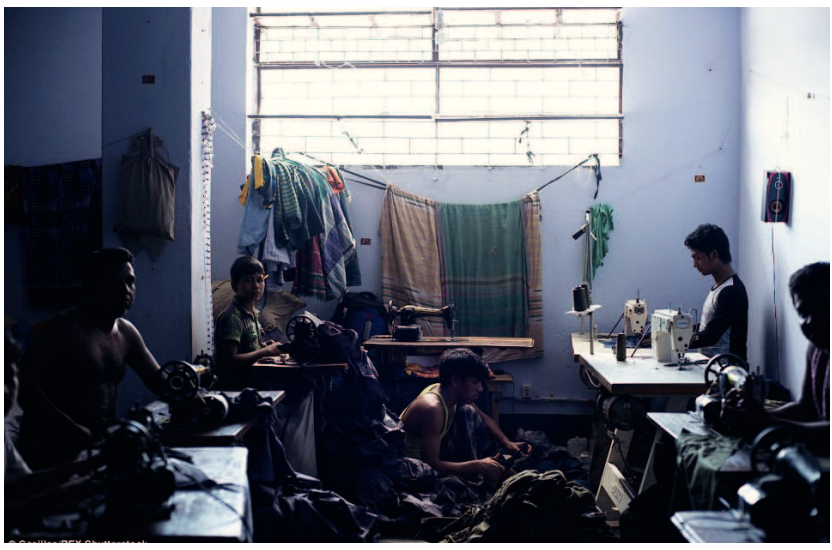

Figura 02: Trabalho escravo

Fonte: disponível em: <https://millenio.wordpress.com/category/libertadesclavitud/>

Morgan em The True Cost (2015) relata a triste tragédia ocorrida em Dhaka, Bangladesh, em abril de 2013, onde funcionava um complexo têxtil num prédio de três andares, o Rana Plaza, que desabou em razão do descumprimento de normas de segurança e pela pressão dos donos para a continuidade das atividades no local, mesmo sabendo do alerta de risco. Mais de mil pessoas morreram nesse acidente.

Esse é um exemplo do que a ganância e a falta de ética podem representar para os seres humanos, obrigados a se submeter a longas jornadas de trabalho em situações precárias, sem iluminação adequada, num ambiente de risco e desordem. Empresas clandestinas possuem máquinas depreciadas, sem cuidado com a ergonomia, pagam salários muito menores do que é o justo para a categoria, com a justificativa da necessidade de alavancar a economia.

\subsection{Contexto econômico do consumismo de} moda

Além da falta de ética, questões econômicas influenciam o consumismo. É fundamental para o país manter uma boa economia, trata-se de uma questão de sobrevivência. Mas, no que se refere ao consumo de moda, principalmente para os países subdesenvolvidos, isso se torna prioridade e tudo e todos que estão ligados ao processo ficam em segundo plano. Todas as irregularidades apontadas anteriormente são consideradas normais e inevitáveis.

O sistema econômico e político é injusto e tem falhas. No documentário produzido por Morgan (THE TRUE COST, 2015), funcionários da indústria da moda são agredidos e até mortos pela polícia a mando do governo e empresas, pelo fato de reivindicarem seus direitos, na luta por um salário mínimo decente. Para esses países, são inadmissíveis protestos ou greves na busca de condições melhores, não existe nada na constituição a seu favor, e eles se colocam à mercê de chantagem e exploração de empresas que visam apenas à valoração de sua marca, acreditando ser a única maneira para o crescimento. Morgan faz uma análise do nosso sistema, o capitalismo de consumo: o governo necessita que haja consumo em altos níveis, trata-se do combustível da economia, e a maioria das pessoas adere a isso (THE TRUE COST, 2015). O problema são os custos altíssimos que a sociedade paga para obter esses resultados.

Além da grave situação das pessoas envolvidas nesses processos, a crescente procura pela terceirização e importação de produtos do vestuário em países como a Ásia afeta diretamente a economia brasileira, que sofre com a concorrência desleal e a perda em investimentos nacionais. Conforme a Associação Brasileira da Indústria Têxtil e de Confecção (ABIT) (2017), as vendas no comércio brasileiro estão sendo afetadas pela introdução de produtos importados, sobretudo da Ásia, e vêm crescendo progressivamente. A participação no mercado em 2003 era de 1,26\% e em 2014 passou para 15\% - crescimento de $614 \%$ em apenas nove anos.

Lamentavelmente, os países asiáticos reduzem os preços de seus produtos por meio da exploração do ser 
humano, do trabalho escravo, estando por trás das negociações empresas de renome. Além das perdas na economia e ética, tem-se o impacto ambiental gerado pelo consumismo.

\subsection{Contexto ambiental do consumismo de moda}

Em todo o mundo, relatos destacam o que a indústria têxtil/de moda está causando ao meio ambiente; ela é considerada uma das mais poluentes do mundo. Tendo em vista que é uma das grandes produtoras, dando ênfase, novamente, ao contexto econômico, a indústria da moda movimenta a economia e é foco no mundo inteiro. Segundo dados da ABIT (2017) quanto ao volume de artigos de vestuário produzidos, a Ásia é responsável por 73\% da produção, ficando o Brasil com a quarta posição entre os maiores produtores mundiais.

Os altos índices de produção refletem-se em toda a cadeia produtiva do setor têxtil e da moda. Todos os processos de manufatura são responsáveis diretamente pelo impacto dos seus resíduos na natureza, pela quantidade de lixo produzida e pelo descarte. Além disso, os clientes finais têm importante responsabilidade nos seus atos, com a compra, o uso e o descarte dos produtos provenientes da indústria da moda.

Muitos acreditam que fazendo doação de suas roupas descartadas estarão realizando uma ação sustentável, passando a deixar de fazer parte do problema, mas essa é uma das questões consideradas graves na natureza. Morgan apresenta vários pontos negativos relacionados à doação de roupas, como no Haiti, que várias lojas acabaram fechando suas portas por conta do alto número de doações entregues ao país - as vestimentas eram colocadas na rua para livre escolha da comunidade. Outro local, também com vulnerabilidade social, mostra enormes pilhas de roupas e tecidos abandonados (a maioria vinda dos Estados Unidos), que não são biodegradáveis e que, com o tempo, liberam gases tóxicos no ar (THE TRUE COST, 2015).

A maior parte da população, principalmente a classe baixa, que possui menos informação, não conhece o processo produtivo das peças do vestuário, os caminhos percorridos até chegar ao consumidor nem o prejuízo causado à natureza. Ao comprar uma simples camiseta de algodão, por exemplo, Berlim (2012, p. 32) relata que esse produto consumiu "160 gramas de agrotóxico, uma determinada quantidade de energia e que causou danos sérios ao solo, à água e àqueles que trabalharam no cultivo do algodão". Na figura 3, temos uma plantação de algodão já sem as folhas, significando que está próxima a colheita.

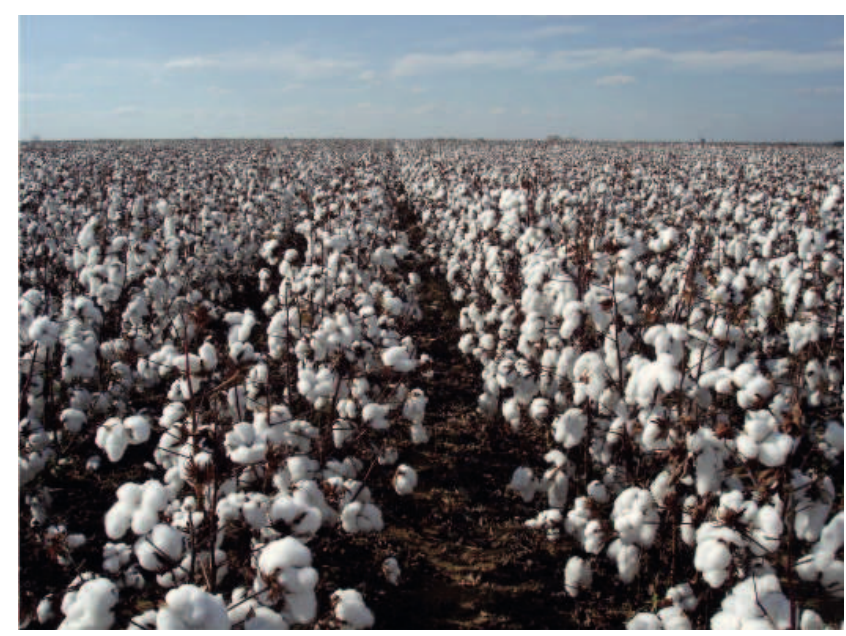

Figura 03: Plantação de algodão

Fonte: disponível em: <http://www.metro.org.br/sebastiao/algodao-0-ouro-branco-do-brasil>

A utilização de agrotóxicos e fertilizantes nas plantações de algodão é justificada pela necessidade de eliminar ou combater pragas que danificam a matéria-prima, mas isso é muito nocivo às pessoas, ao solo e ao lençol freático. Não se percebe que o maior órgão do corpo humano, a pele, está diretamente exposta a esses agentes, podendo causar cânceres e outros problemas de saúde. Morgan relata que cerca de 70 a 80 crianças de uma comunidade de Punjab, na Índia, possuem retardo mental e outros problemas neurológicos em razão do contato com produtos químicos provenientes das pulverizações das lavouras de algodão (THE TRUE COST, 2015). Os próprios agricultores sofrem muito com as doenças. A família, em condições vulneráveis, não consegue disponibilizar aos familiares os tratamentos necessários para possibilitar a reabilitação, causando, muitas vezes, a morte de adultos e crianças. Sem provas concretas da relação da indústria de pesticidas com essas ocorrências, as comunidades locais sofrem sem receber recursos ou indenizações e cada vez mais estão imersas nesse cenário desumano.

É fato que as questões ambientais estão sendo debatidas por algumas corporações com mais seriedade, sendo pauta de discussão em empresas e governo, e muitos buscam adotar medidas sustentáveis. Entretanto, faz-se preciso disseminar essas reflexões aos que mais contribuem com o consumismo, que são os agentes consumidores.

\section{AGENTES SOCIAIS DO CONSUMISMO DE MODA}

Todos esses fatores impulsionam o consumismo em moda, mas existiria tamanha busca por atender a esses elementos se não existissem os agentes consumidores? Essa resposta é simples: não existe mercado sem demanda. Infelizmente, as pessoas são os principais atores desse 
cenário, cada um com a sua particularidade e preferência exclusiva. Com o intuito de atender a desejos e acompanhar as tendências da moda, a sociedade adquire em demasia roupas que, muitas vezes, utilizará uma ou duas vezes antes do descarte.

Adquirir roupas sem necessidade é uma ação moldada por inúmeros fatores que envolvem o ser humano na sociedade, formando o habitus. Conforme Setton (2002, p. 61), "habitus é uma noção que me auxilia a pensar as características de uma identidade social, de uma experiência biográfica, um sistema de orientação ora consciente ora inconsciente".

$\mathrm{O}$ ato de um indivíduo comprar roupas em excesso, mesmo sabendo que os produtos podem ser provenientes de manufatura escrava, ou que aquela compra comprometerá a renda mensal da sua família, é uma característica que vem do meio em que a pessoa está inserida, da sua existência, da educação recebida na família e na escola, dos contatos sociais e da cultura da comunidade. O habitus está ligado com as experiências dos agentes no campo inserido, podendo ser distinta ou ainda distintiva, reunindo características particulares e relacionais de um indivíduo, que tem o poder de escolher pessoas, bens e práticas (BOURDIEU, 2008).

O modo de ser de um ser humano nem sempre foi o mesmo; ele também vem sendo modelado e alterado a cada época. Os valores, o gosto e as prioridades vão sendo substituídos, mesclados, transformados. Setton (2002, p. 66) relata que se pode pensar "a constituição da identidade social do indivíduo moderno a partir de um habitus híbrido, construído não apenas como expressão de um sentido prático incorporado e posto em prática de maneira 'automática', mas uma memória em ação e construção".

Fatores relacionados ao habitus social e ao capital econômico muito influenciam as relações efetuadas na moda. Por um lado, temos a produção e as pessoas envolvidas nesse processo conflituoso, e por outro há uma demanda pertencente a diversos nichos, desde o menos favorecido ao possuidor de maior riqueza - ambos possuem o desejo de se apropriar de bens que, muitas vezes, têm apenas valor simbólico. Scholts (2009) exemplifica essa realidade quando relata que a aquisição de um casaco de luxo acaba tendo finalidade diferente dos seus objetivos principais, que são proteger e aquecer o corpo humano: ele passa a ter valor simbólico, demonstra diferenciação e aceitação em determinada classe e nos lugares por que o indivíduo circula, características semelhantes às do capital simbólico desejado pelo casaco de luxo.

O menos favorecido economicamente, muitas vezes, deixa de adquirir algo necessário para si e sua família, ou realiza a compra com pagamento parcelado, enquanto para quem possui riquezas o consumismo já faz parte do cotidiano. Ou seja, ele adquire e possui conforme seu desejo, destacando a distinção entre as classes. Essa realidade revela um agente social voltado para o consumo desenfreado.

O exemplo do casaco traz uma peça de luxo mais cara, mas a compra de produtos baratos em demasia também é muito forte. Peças do vestuário com procedência duvidosa são adquiridas por até $\mathrm{R} \$ 10$ no mercado a todo o tempo, porém sua baixa qualidade torna o produto quase descartável. Esse cenário, no entanto, abrange um momento em transição. Tendências revelam um consumidor voltado ao consumo consciente, mais envolvido em práticas sustentáveis e sociais, revelando que mudanças nas práticas dos agentes podem trazer mudanças à sociedade. Conforme Rodrigues (2005, p. 9), "a organização social é o resultado do complexo cultural formatado a partir de conhecimentos, crenças, valores e símbolos, revelando-se como um sistema em constante mutação".

Sendo os agentes sociais protagonistas da evolução do consumo na sociedade e em todo o contexto envolvido, evidencia-se que informação e conhecimento são necessários para a mudança no habitus.

\section{CENÁRIOS E TENDÊNCIAS RELACIONADAS AO CONSUMO DE MODA}

Os cenários apresentados no texto propiciaram a visão da necessidade de se antecipar as possíveis mudanças, e pesquisas falam de uma quarta Revolução Industrial, exibindo um cenário mais positivo para o futuro em relação às questões levantadas. Para estarem preparados para essas transformações, várias empresas e órgãos que fomentam a indústria têxtil e da moda, como o Serviço Brasileiro de Apoio às Micro e Pequenas Empresas (Sebrae) e a ABIT, se uniram para analisar as tendências e se posicionarem, vislumbrando soluções para essa realidade próxima. Bruno (2016, p. 36) explica que "o termo Indústria 4.0 se refere à Quarta Revolução Industrial e é frequentemente entendido como aplicação do conceito genérico de Sistemas Ciberfísicos nos sistemas de produção".

O uso da tecnologia da informação, da internet das coisas e da robótica no setor têxtil e de moda é um exemplo dos caminhos encontrados para solucionar as demandas resultantes das mudanças. Segundo Bruno (2016, p. 63), "a indústria de 2030 será radicalmente diferente da de hoje e praticamente irreconhecível do ponto de vista de trinta anos atrás". Por muito tempo, as indústrias da 
moda buscaram na importação uma maneira de enfrentar a desleal concorrência. Bruno (2016) relata que, após o deslocamento da manufatura do Brasil e de outros países do mundo para indústrias da Ásia, o aumento nos custos com transporte e energia, nos salários, além da cobrança por qualidade e diversidade, ficou explícito, sendo necessário revisar a postura da importação. Diversos trabalhos sugerem que o retorno da manufatura têxtil e moda aos países de alta complexidade econômica seja adequado.

Com reflexo direto na economia, processos industriais que antes levavam dias em execução precisam apenas de horas, com diminuição das distâncias e do uso de tecnologia, da automação e da internet nas comunicações. Um exemplo disso é o fato de que as peças do vestuário serão produzidas por impressão em três dimensões (3D). Esse tempo talvez seja um pouco mais longo para o Brasil, país no qual as mudanças normalmente ocorrem posteriormente aos países desenvolvidos. Bruno $(2016$, p. 63) escreve que "o termo indústria, nos próximos anos, estará cada vez mais associado à complexidade de sistemas ciberfísicos, autônomos, integrados e robotizados". De acordo com o mencionado teórico, o emprego de tecnologias e sistemas de virtualização das cadeias de valor, juntamente com a automação na confecção e a integração dos serviços ao consumidor, permite que novos e pequenos empreendedores voltem a ser competitivos, com customização de produtos e tempos de fabricação menores que os obtidos em uma produção convencional.

A indústria da moda, cuja finalidade está em atender às exigências do mercado e da sociedade, acredita que as mudanças previstas vão disseminar a integração de setores, de empresas diferentes e de serviços. "As novas tecnologias de materiais, produtos e processos, e a hibridização da manufatura com os serviços, todos obedecendo aos princípios de consumo e produção sustentável, criarão novos conceitos de produtos e serviços" (BRUNO, 2016, p. 65).

Processos que antes ocorriam separadamente começam a se integrar, para que as soluções e os resultados sejam mais rápidos. Esse conceito não é novo. Na primeira edição do livro Culturas híbridas: estratégias para entrar e sair da modernidade, de 1997 (esse livro em 2013 passou pela sua quarta edição), Canclini já conceituava hibridação: "Hibridação são processos socioculturais nos quais estruturas ou práticas discretas, que existiam de forma separada, se combinam para gerar novas estruturas, objetos e práticas" (CANCLINI, 2013, p. 19).

Atualmente existem segmentos nas comunidades em que valores como a ética do consumo em moda e do crescimento sustentável é norteadora de ações. Muitas empresas fiscalizam o processo dentro de facções e só contratam os serviços se estiverem conforme os padrões da legalidade e as normas da contratante, pois esta será corresponsável no caso de qualquer irregularidade. Pesquisas demonstram que o mercado valoriza e adquire mais produtos do vestuário de empresas que contribuem com causas sociais e que não estão envolvidas na escravidão contemporânea. Bruno (2016, p. 66) escreve que, "no Brasil, o estudo revelou que $75 \%$ afirmaram que comprariam um artigo por uma boa causa, enquanto cerca de 95\% atuariam como porta-vozes de ações de responsabilidades socioambientais corporativas". Exemplos de empresas atuando nesse âmbito no mercado são: a Reserva, empresa do vestuário no Rio de Janeiro, que doa cinco pratos de alimento a cada produto vendido; e a BeCauz, empresa localizada em Santa Catarina, que destina 50\% do lucro do produto vendido para a organização não governamental (ONG) que o cliente escolher.

Esse novo cenário também está voltado para a consciência com o meio ambiente. A indústria da moda não pode ser mais protagonista dessa degradação, e encara-se uma necessidade de mudança. Bruno $(2016$, p. 75$)$ afirma que, "por pressões crescentes de consumidores e de movimentos sociais, políticas públicas e estratégias privadas têm enfatizado a cultura da sustentabilidade como um novo valor a ser adicionado ao valor econômico". As indústrias sujas da área têxtil estão cada vez mais sendo cobradas por alterações nos seus processos de manufatura, para que passem a não agredir o meio ambiente.

Para enfrentar as mudanças que ocorrerão nesses cenários, tendências já consideradas concretas para os pesquisadores, a sociedade e as empresas deverão estar preparadas, novos empreendedores terão oportunidade, e a busca pelas possíveis soluções mencionadas serão necessárias para que as empresas permaneçam no mercado e prosperem. Muitas empresas, antecipadas pelos estudos realizados, já visam a alterações nas suas estruturas. Onde antes existiam o individualismo e apenas a visão de concorrência, hoje há a união de esforços para enfrentar um futuro repleto de inovações tecnológicas.

\section{CONSIDERAÇÕES FINAIS}

$O$ artigo refletiu acerca do consumismo na contemporaneidade, focando no campo da moda. Levantaram-se considerações relacionadas à ética, à economia e ao meio ambiente, envolvendo o agente consumidor e as tendências apontadas para o setor têxtil e de moda, como: trabalho escravo, altos custos pagos para manter a economia e poluição. 
No tocante à ética, verificou-se que as práticas dos agentes sociais quanto à aquisição de objetos estão vinculadas à educação e cultura de um país. Relacionam-se, ainda, com o campo no qual os agentes estão inseridos, na busca por manter ou alcançar distinção social. Vinculam-se, também, com o habitus, que é o princípio gerador das práticas humanas e que envolve as experiências dos agentes a partir da família, escola e sociedade em geral. Nesse sentido, os países subdesenvolvidos são os que mais sofrem, pois investimentos na educação não são priorizados.

Além da ética, questões econômicas favorecem e incentivam o consumismo. Países subdesenvolvidos têm como principal propósito impulsionar a economia, por meio de empreendimentos que resultem na arrecadação de impostos; não raro, postergam projetos voltados à educação e ao meio ambiente, gerando desconforto $\mathrm{e}$ insatisfação social.

O artigo evidenciou que o consumismo também é prejudicial ao meio ambiente. Faz-se necessário que os processos sejam revistos, buscando-se maneiras sustentáveis para realizar cada etapa nos diversos setores existentes, desde a produção das fibras - naturais ou sintéticas - até o descarte final. A produção e o consumo em moda não poderão ser desvinculados, são necessários para os agentes sociais, mas é possível atuar de maneira coerente com a realidade atual, tendo consciência de que práticas produtivas e consumismo refletem diretamente na natureza.

Conclui-se, com base nas considerações expressas no artigo, que a massa da população voltada para o consumo consciente, com conceitos éticos, que acredita nas mudanças e atua em prol delas, vem crescendo lentamente. O consumo consciente configura-se como tendência, todavia os envolvidos nos movimentos ativistas não conseguem proliferar a sua causa na velocidade necessária para conter o paradigma consumista. Está previsto um cenário promissor em relação à introdução de tecnologias, por meio das quais empresas do setor têxtil/de moda do Brasil e do mundo vêm evoluindo. É imprescindível que mudanças ocorram também com os agentes consumidores: conscientizar-se de que o consumismo de moda causa danos e preocupar-se com o meio ambiente e com as pessoas envolvidas, entendendo que ações sociais e de evolução humana devem ser realizadas, na tentativa de diminuir diferenças sociais e impactar no futuro.

\section{REFERÊNCIAS}

ASSOCIAÇÃO BRASILEIRA DA INDÚSTRIA TÊXTIL E DE CONFECÇÃO (ABIT). 0 poder da moda: cenários, desafios, perspectivas. Agenda de competitividade da indústria têxtil e de confecção brasileira 2015 a 2018. Disponível em: <www.abit.org.br>. Acesso em: 9 maio 2017.

BARBOSA, Ligia. Sociedade de consumo. Rio de Janeiro: Zahar, 2004.

BAUMAN, Zygmunt. Vida para consumo: a transformação das pessoas em mercadorias. Rio de Janeiro: Zahar, 2008.

BERLIM, Lilyan. Moda e sustentabilidade: uma reflexão necessária. São Paulo: Estação das Letras e Cores, 2012.

BOURDIEU, Pierre. Razões práticas: sobre a teoria da ação. 9. ed. São Paulo: Papirus, 2008.

BRUNO, Flavio da Silveira. A quarta Revolução Industrial do setor têxtil e de confecção: a visão de futuro para 2030. São Paulo: Estação das Letras e Cores, 2016.

CANCLINI, Nestor Garcia. Culturas híbridas: estratégias para entrar e sair da modernidade. 4 ed. São Paulo: Edusp, 2013.

FORTY, Adrian. Objetos de desejo. São Paulo: Cosac Naify, 2007.

LEONARD, Annie. A história das coisas: da natureza ao lixo, o que acontece com tudo que consumimos. Rio de Janeiro: Zahar, 2011.

PENNA, Carlos Gabaglia. O estado do planeta: sociedade de consumo e degradação ambiental. Rio de Janeiro: Record, 1999.

PIETROCOLLA, Luci Gati. Sociedade de consumo. 2. ed. São Paulo: Global, 1986.

RODRIGUES, Irene G. Antropologia e design: o olhar antropológico do designer. São Paulo: Rosari, 2005.

SALDANHA, Patrícia Golçalves; ASSIS, Eduardo Aguiar. A inatingível meta do intangível e as consequências sociais: do The True Cost à moda livre. Revista Eletrônica de Comunicação, Informação e Inovação em Saúde, 2016. 
SCHOLTS, Robinson H. Habitus de classe expressado pelo capital simbólico: uma revisão da obra de Pierre Bourdieu A Distinção. Ciências Sociais Unisinos, 2009.

SETTON, Maria da Graça Jacintho. A teoria do habitus em Pierre Bourdieu: uma leitura contemporânea.

Revista Brasileira de Educação, 2002.

THE TRUE COST. Direção: Andrew Morgan. Produção: Michael Ross. 2015. Disponível em: <https://itunes. apple.com/us/movie/the-true-cost/id989035329?ign-mpt=uo\%3D6>. Acesso em: 19 jun. 2015.

\section{AUTORES}

ORCID: https://orcid.org/0000-0002-6384-6068

ELENIR CARMEN MORGENSTERN, DRA.|Universidade da Região de Joinville |PPGDesign | Joinville, SC. Brasil | Correspondência para: Rua Paulo Malschitzki, 10 - Zona Industrial Norte Joinville - SC - 89219-710 | E-maill: elenir.m@gmail.com

ORCID: https://orcid.org/0000-0002-2791-8044

SILVANA SILVA REITER WITKOSKI. | Universidade da Região de Joinville |PPGDesign | Joinville, SC. Brasil |Correspondência para: Rua Paulo Malschitzki, 10 - Zona Industrial Norte Joinville - SC - 89219-710 |E-maill: vanawitkoski@gmail.com

\section{COMO CITAR ESTE ARTIGO}

WITKOSKI, Silvana Silva Reiter; MORGENSTERN Elenir Carmen. Consumismo: uma Reflexão Acerca das Aquisições no Campo da Moda. MIX Sustentável, [S.I.], v. 4, n. 3, p. 67-75, out-mar. 2018. ISSN 24473073. Disponível em: <http://www.nexos.ufsc. br/index.php/mixsustentavel>. Acesso em: dia mês. ano. doi:https://doi.org/10.29183/2447-3073.MIX2018. v4.n3.67-75.

DATA DE ENVI0: 03/09/2018

DATA DE ACEITE: $11 / 09 / 2018$ 